\title{
VIABILIDADE ECONÔMICA DE PROJETO DE MECANISMO DE DESENVOLVIMENTO LIMPO EM ATERRO SANITÁRIO NA CIDADE DE VIÇOSA - MG
}

\author{
Leandro Gomes de Oliveira' \\ Alexandre Bragança Coelho² \\ Caio César Medeiros Costa ${ }^{3}$ \\ Gislaine Aparecida Purgato ${ }^{4}$
}

\section{Resumo}

O Mecanismo de Desenvolvimento Limpo (MDL) foi desenvolvido no Protocolo de Kyoto com o intuito de que os países signatários reduzissem suas emissões de gases dos efeitos estufa. Um que está em amplo desenvolvimento no Brasil são os projetos de MDL aplicados a aterros sanitários. O custo de implantação de aterros sanitários é uma das principais restrições a empreendimentos desse tipo, especialmente em municípios pequenos. O Mecanismo de Desenvolvimento Limpo (MDL), ao permitir que os municípios aufiram renda com a venda de créditos de carbono por longo tempo após sua implantação, poderia funcionar como uma forma de estimular a implantação desses aterros e diminuir a restrição de custos de municípios pequenos. Nesse sentido, o presente trabalho teve como objetivo fazer o cálculo da viabilidade econômica de se implantar um projeto de MDL no aterro sanitário na cidade de Viçosa-MG. Para investigar a viabilidade econômica deste projeto, foram calculados o Valor Presente Líquido (VPL) e da Taxa Interna de Retorno (TIR). Os cálculos do VPL e TIR mostraram que para que esse projeto seja viável o preço do crédito de carbono teria que ser muito maior do que o comercializado hoje. Por isso, afirma-se que o projeto é inviável economicamente. A principal razão para este fato é que a quantidade de lixo produzida diariamente pela cidade é

\footnotetext{
Mestrando em Engenharia de Produção-UFSCar. Email: leandrobaquim@yahoo.com.br

Professor Associado do Departamento de Economia Rural. Universidade Federal de Viçosa. E-mail: acoelho@ufv.br Doutorando do Departamento de Administração com enfoque em Administração Pública. Fundação Getúlio vargas. E-mail: caiocesq@hotmail.com

Graduanda em Bioquímica. Universidade Federal de Viçosa. E-mail: gislaine.aparecida@ufv.br
} 
relativamente pequena (19 toneladas/dia). Uma possível maneira para esse projeto se concretizar sem causar prejuízo para a cidade seria a formação de um consórcio entre diversas cidades visando aumentar a quantidade de resíduos sólidos armazenados diariamente, bem como a divisão dos custos de implementação e operacional no aterro sanitário.

Palavras-chave: Análise Econômica de Projetos; Gestão de Projetos; Viabilidade econômica.

\section{Classificação JEL: Q5}

\section{INTRODUÇÃO}

O desenvolvimento econômico vem sendo acompanhado por um aumento de degradação ambiental. O início desse processo ocorreu com a Revolução Industrial, onde a mecanização utilizava como fonte de abastecimento a queima de carvão mineral. A partir disso, a economia mundial se desenvolveu basicamente através de energia fóssil (petróleo, carvão e gás natural) levando ao acúmulo de emissão de gases do efeito estufa na atmosfera (GEE`s).

Segundo Bortholin e Guedes (2007), o efeito estufa consiste, no aquecimento da superfície da Terra, causada pela irradiação de $\mathrm{CO}_{2}$ (dióxido de carbono) e outros gases. Esse aquecimento é imprescindível para a existência de vida no planeta. Entretanto, a ação humana tem exacerbado esse efeito natural causando grandes alterações climáticas em escala global.

Observando isso, diversos acordos têm sido institucionalizados a fim de reduzir as emissões de GEE`s. Segundo Cotta (2005), as políticas internacionais sobre mudanças climáticas surgiram em 1988, quando a Assembleia Geral das Nações Unidas declarou que a mudança climática era uma preocupação mundial. Diante desse quadro, foram realizadas as Conferências das Partes (COP's), que estabelecia às diretrizes de combate as mudanças climáticas. Uma das mais importantes foi a COP3, que ocorreu em Kyoto no Japão em 1997, ficando acordado quais seriam as metas e prazos das emissões de cada país signatário. 
Para isso foram criados os mecanismos de flexibilização. Esses mecanismos são utilizados para que os países signatários possam alcançar suas metas estipuladas através de vendas de créditos de carbono e implementação de projetos. O Mecanismo de Desenvolvimento Limpo (MDL) é um dos tipos de mecanismos de flexibilização. Seu intuito é que os países desenvolvidos financiem projetos de redução de emissões ou absorção de carbono em países em desenvolvimento, contribuindo assim para o desenvolvimento sustentável desses países. Em contrapartida, estes países obteriam Certificados de Emissões Reduzidas (CER's) podendo fazer o abatimento das metas que estes devem cumprir (FRANGUETTO; GAZANI, 2002).

Os mecanismos de flexibilização podem ser aplicados a diversos escopos de projetos (MCT, 2010). Um que está em amplo desenvolvimento no Brasil são os projetos de MDL aplicados a aterros sanitários. Esses são considerados as formas de disposição de lixo mais apropriadas que menos impactam ambientalmente. Desse modo, um projeto de MDL aplicado a um aterro sanitário visaria à redução de emissão de gases do efeito estufa, bem como reduziria os impactos ambientais gerados pelos resíduos sólidos.

No que se refere ao Estado de Minas Gerais, o cenário da gestão de resíduos sólidos não é diferente do resto do país. O estado produz 15.664 toneladas por dia de lixo, totalizando $12 \%$ da produção nacional. Desses, 4.778,6 toneladas (30\%) são destinadas a lixões, $4.181,6$ toneladas $(26,7 \%)$ vão para aterros controlados e 5.296,8 toneladas (43,3\%) são enviadas para aterros sanitários (IBGE, 2000).

O presente trabalho visa verificar se existe viabilidade econômica para se implantar um aterro sanitário na cidade de Viçosa- $\mathrm{MG}^{5}$ e assim utilizar o mecanismo de desenvolvimento limpo (MDL) para gerar créditos de carbono e consequentemente sanar os custos de implementação do aterro sanitário. No entanto, para atingir o objetivo geral será necessário percorrer os seguintes objetivos específicos:

- Fazer o levantamento dos custos para se implementar um aterro sanitário;

O município possui um aterro controlado sendo operacionalizado, este é um local utilizado para o despejo do lixo coletado, com cuidado de, após a jornada de trabalho, cobri-lo com uma camada de terra, sem causar danos ou riscos à saúde pública e a segurança, minimizando os impactos ao meio ambiente. 
- Calcular as emissões de metano do aterro de Viçosa com a não-implantação do projeto de MDL (linha-de-base);

- Projetar as receitas esperadas com a comercialização de créditos de carbono provenientes da implantação do projeto de MDL.

\section{REFERENCIAL TEÓRICO}

\subsection{Projeto de MDL}

Os projetos de MDL e o mercado de crédito de carbono foram criados através de decisões de âmbito global para facilitar a redução de emissões de gases do efeito estufa (GEE's) na atmosfera. Assim, ocorreu um estimulo da economia e da sociedade a obter a cota de reduções de GEE's por meio de projetos de fontes renováveis e sustentáveis. O MDL é um dos principais modelos de flexibilização do Protocolo de Kyoto: estes são geralmente executados por empresas que visam grandes oportunidades de negócios, onde cada tonelada de gases do efeito estufa reduzida é comercializada no mercado de crédito de carbono (VIDIGAL, 2011).

Os projetos de MDL não visam somente o retorno financeiro, eles se enquadram em todas as esferas sociais. O Manual para Submissão de Projetos é um documento que passa pela aprovação da Comissão Interministerial de Mudança Climática para que se possam realizar atividades na área de Mecanismo de Desenvolvimento Limpo (BRASIL, 2005). Esse documento deve conter algumas atividades que contribuirão para o desenvolvimento sustentável da região. Segundo PENTEADO e MELO (2008), alguns desses aspectos podem ser:

- $\quad$ Contribuição para a sustentabilidade ambiental: avalia os impactos ambientais locais com a execução do projeto.

- Contribuição para o desenvolvimento das condições de trabalho e geração líquida de emprego: avalia o compromisso do projeto com as responsabilidades sociais e trabalhistas, programas de saúde e educação e direitos civis. 
- $\quad$ Contribuição para a distribuição de renda: avalia os efeitos diretos e indiretos do projeto sobre a qualidade de vida das populações de baixa renda.

- $\quad$ Contribuição para a capacidade de desenvolvimento tecnológico: avalia o grau de inovação de tecnologia na execução do projeto.

- $\quad$ Contribuição para a integração regional e articulação com outros setores: contribuição para o desenvolvimento regional pode ser medida a partir da integração do projeto com outras atividades socioeconômicas na região.

Com a implantação de um projeto de MDL, surgem dois importantes conceitos que devem ser ressaltados: a linha de base e a adicionalidade. A linha de base representa todas as emissões de gases do efeito estufa (GEE's) sem a presença de um projeto de redução ou remoção destes gases. O conceito de adicionalidade consiste na redução dos gases na presença de um projeto apropriado. Esta diferença entre a linha de base e a adicionalidade determina se o projeto de MDL será aprovado, pois deve-se comprovar que este contribui de forma positiva na redução de gases (LEME e CUNHA, 2004).

Observa-se um aumento da preocupação mundial com relação às conseqüências das ações antrópicas sobre meio ambiente e por isso há uma necessidade mundial de diminuições de emissões. Com isso, os meios de flexibilização do Protocolo de Kyoto, especialmente os projetos de MDL, são uns dos meios de se alcançar esses objetivos e o Brasil apresenta grande potencial para implementar esse tipo de projeto. O gráfico $1^{\mathrm{a}}$ apresenta a distribuição em percentual dos principais países que efetuam projetos de MDL.

Percebe-se pelo gráfico 1 que, os projetos de MDL estão sendo desenvolvidos por todo o mundo. A China é a principal representante no desenvolvimento de projetos de MDL. Ela é responsável por $37 \%$ de todos os projetos do mundo, seguida pela Índia, que implementa cerca de $27 \%$ do total mundial e o Brasil, que fica com o $3^{\circ}$ lugar, com $7 \%$ da capacidade mundial. Isso acontece porque o Brasil já apresenta uma matriz energética bem limpa, advinda principalmente da geração de energia elétrica das hidrelétricas. Ao contrário, as matrizes energéticas da China e Índia ainda são baseadas principalmente no carvão mineral e petróleo, componentes altamente poluidores. 
Viabilidade econômica de projeto de mecanismo de desenvolvimento limpo em aterro sanitário na cidade de Viçosa - MG

Gráfico 1. Participação no total de atividades de projeto no âmbito do MDL no mundo.

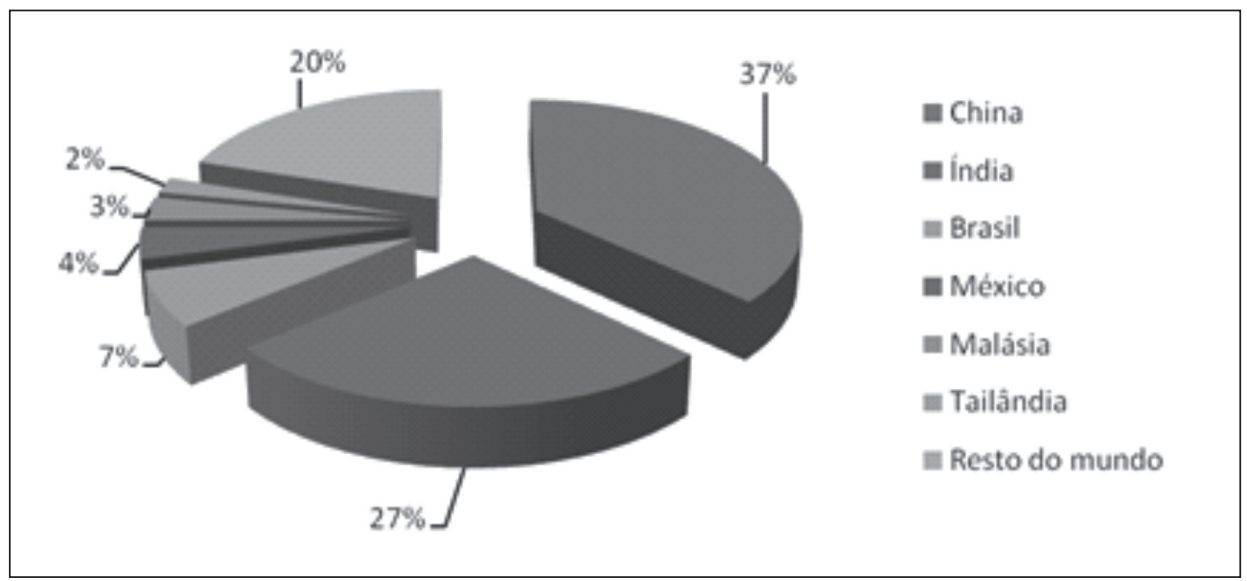

Fonte de dados: Ministério da Ciência e Tecnologia (2010).

Em relação ao potencial de redução de emissões de gases do efeito estufa, o Brasil, apresentava um grande potencial para reduzir essas emissões. O gráfico 2 mostra o potencial de redução de emissões mundiais.

Gráfico 2. Participação no Potencial de Redução de emissões mundiais.

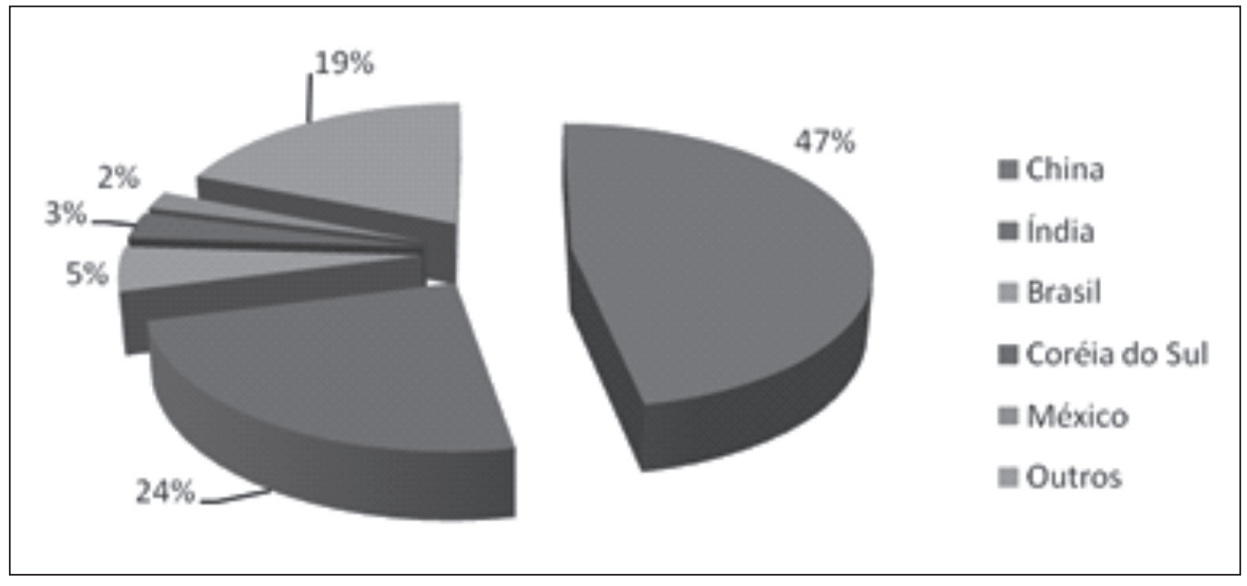

Fonte de dados: Ministério da Ciência e Tecnologia (2010). 
Nota-se pelo gráfico 2 que a China apresenta a maior potencial para reduzir as emissões de gases do efeito estufa, com um total de 3.291.424.886 toneladas de $\mathrm{CO}_{2}$. Em seguida, a Índia com 1.668.521.491 toneladas de $\mathrm{CO}_{2}$. O Brasil apresentava um potencial de redução de 381.151 toneladas de $\mathrm{CO}_{2}$, correspondendo a somente $5 \%$ do total. Apesar disso, este possui uma abundância de recursos naturais que podem ser utilizados para impulsionar o mercado de crédito de carbono no país.

Os projetos de MDL apresentam uma grande diversidade quanto a sua aplicação, pois podem ser aplicados em diversos setores da sociedade. No Brasil, há uma predominância desses projetos na área de energia renovável, especialmente no aproveitamento do bagaço de cana para geração de energia. O gráfico 3 apresenta a divisão de projetos por escopo setorial no Brasil.

Gráfico 3. Número de Projetos por Escopo Setorial.

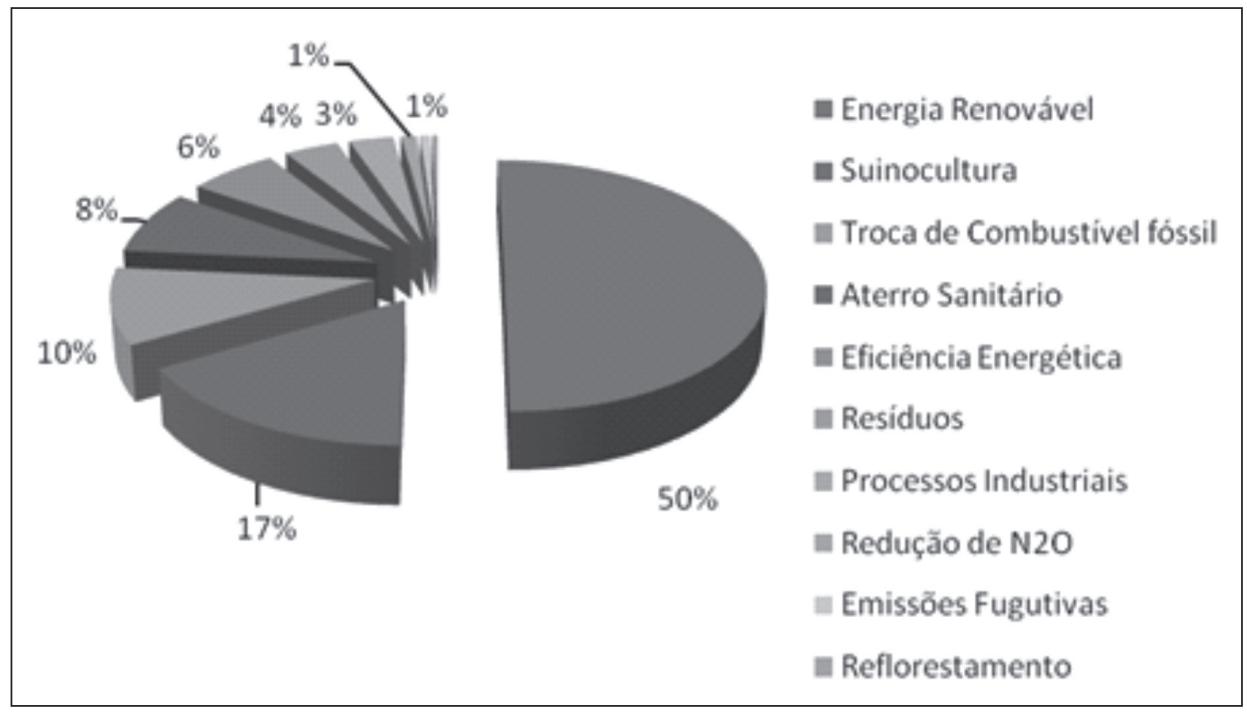

Fonte: Ministério da Ciência e Tecnologia (2010).

Percebe-se a partir do gráfico 3 que, a maioria dos projetos de MDL está envolvida com fontes renováveis $(50 \%)$. Os aterros sanitários ocupam a $4^{\circ}$ colocação, com uma participação significativa no cenário nacional. Apesar de ser somente $8 \%$ do total, essa área de projetos vem aumentando. Isso 
ocorre devido ao grande potencial de geração de créditos de carbono. Além disso, esta é a forma mais segura de disposição de lixo, pois seu tratamento visa a maior redução dos impactos ambientais.

\subsection{Resíduos sólidos e Aterro sanitário}

O processo de desenvolvimento está associado à produção de resíduos. $\mathrm{Na}$ maioria das vezes, estes resíduos não recebem o tratamento adequado para minimizar seu impacto. Segundo IBGE (2000), o Brasil não apresenta um cenário satisfatório na gestão de resíduos urbanos, pois $63,6 \%$ dos municípios brasileiros não dão um destino adequado para seus resíduos.

Quando o lixo não é destinado a um local apropriado, acarreta a diversos problemas para a sociedade. Sua disposição inadequada causa a degradação do meio ambiente e problemas de saúde, comprometendo a qualidade de vida. A proliferação de doenças é uma das consequências, pois os vetores se alojam no lixo, fazendo deste seu habitat (CARVALHO, 2011). Esses ali encontram um ambiente propício para crescer e se desenvolver, podendo assim disseminar doenças que podem levar a morte, como leptospirose, dengue, amebíase, peste bubônica, diarreias infecciosas, botulismo, tétano, etc (FUNASA, 2000).

A poluição das águas é outro problema causado pelo destino inadequado do lixo. Rios, mares e lençóis freáticos são contaminados, fazendo com que a água fique imprópria para o consumo. O lixo a céu aberto, quando acumulado, libera um líquido tóxico chamado chorume, que é resultado da degradação anaeróbia (sem presença de oxigênio) da matéria orgânica. $\mathrm{O}$ chorume é um lixiviado e quando aflui para rios e lençóis freáticos, causa sua contaminação. Os lixiviados são definidos como os líquidos provenientes de três fontes principais: umidade natural dos resíduos sólidos, água de constituição dos diferentes materiais que sobram durante o processo de decomposição e líquido proveniente de materiais orgânicos que são eliminados pelas enzimas expelidas pelas bactérias (REICHERT, 2000).

No âmbito social, existem pessoas que sobrevivem da utilização do lixo. O lixo, quando é jogado a céu aberto, atrai populações de baixa renda, que por meio da captação de materiais recicláveis buscam obter alguma remuneração. Esse tipo de trabalho torna-se um problema para a sociedade, 
pois os catadores estão inseridos em um ambiente propício à disseminação de doenças e que apresenta condições subumanas de trabalho (CAVALCANTE; FRANCO, 2007) .

A grande quantidade de resíduos produzida deve-se ao crescente poder aquisitivo e a melhora do padrão de vida da população. Com a urbanização e industrialização, as pessoas consomem cada vez mais produtos industrializados, gerando uma enorme quantidade de resíduos. Só no Brasil, é estimada a produção de 125 mil toneladas de lixo por dia, sendo que $47,1 \%$ são destinados a aterros sanitários, $22,3 \%$ a aterros controlados e 30,5\% a lixões (IBGE, 2000). Nota-se que a utilização de aterros sanitários para a disposição no Brasil corresponde a maior parte. Isso mostra que as prefeituras tem buscado minimizar os impactos causados pelo lixo destinando a forma que menos impacto ambiental e socialmente.

Aterro sanitário é a forma de disposição do lixo em um terreno fundamentado em critérios de engenharia e normas operacionais específicas. Nele, o lixo é coletado após cada jornada de trabalho, mas diferentemente do aterro controlado, tem-se a preocupação e obrigação de se realizar o tratamento do chorume antes deste retornar a meio ambiente. Para isso, realizam-se inspeções periódicas para medir o $\mathrm{PH}$ da água, verificando se houve ou não contaminação dos lençóis freáticos da região (IBGE, 2000).

A Lei $\mathrm{n}^{\mathrm{o}}$ 10.257/2001, denominada Estatuto das Cidades, que foi assinado em 2001, obriga cidades com mais de 20 mil habitantes a fazer Planos Diretores para gerenciamento de resíduos sólidos (BRASIL, 2001). A motivação desta obrigação foi estimular pequenas cidades a implantarem aterros sanitários, já que o crescimento na implantação deste tipo de instalação, o destino final mais seguro para os resíduos sólidos, se deu exclusivamente em algumas grandes cidades - onde o volume de lixo por habitante é mais alto. De acordo com dados do IBGE, citados por Veloso e Costa (2004), nos municípios com até 50 mil habitantes, mais de 60\% dos resíduos ainda são destinados aos lixões a céu aberto.

A responsabilidade da gestão de resíduos sólidos é quase sempre do município. Além de cumprir as legislações para implantar um aterro sanitário, a prefeitura tem que arcar com os custos de construção e administração do aterro. $\mathrm{O}$ inicio se dá com a elaboração de um projeto inicial por engenheiros especializados. Posteriormente, os custos de um aterro sanitário são prove- 
nientes da construção da estrutura física do aterro e de manutenção do local após iniciadas as atividades. Os investimentos iniciais são principalmente para aquisição do terreno para a construção do aterro. Segundo Lupatini (2002), a seleção do local deve reunir algumas características, dentre elas: minimizar a possibilidade de existência de impactos ambientais negativos aos meios físicos, bióticos e antrópico; minimizar os custos envolvidos; minimizar a complexidade técnica para viabilização do aterro; maximizar a aceitação pública, indo ao encontro dos interesses da comunidade.

Depois são incorridos os custos da estrutura do aterro como: administração; usina de triagem, que é o local onde o lixo é selecionado entre orgânico e inorgânico; as lagoas anaeróbias e facultativas, onde se faz o tratamento do chorume; as plataformas, onde o lixo é depositado para ser enterrado no final de cada dia e a captação de gás que é liberado da decomposição do lixo. Devido a todos esses custos, municípios de pequeno porte apresentam grande dificuldade para implantação de aterros sanitários.

Além disso, segundo o CONAMA (2002), existe uma dificuldade adicional por parte dos municípios de pequeno porte em implementar sistemas de disposição final de resíduos sólidos: o Licenciamento Ambiental que é emitido por órgãos competentes. Na resolução n 308 de 21 de março de 2002, este estabelece os critérios de licenciamento ambiental para instalação de aterros sanitários, seleção de área e recuperação de áreas degradadas.

Dessa forma, fica claro que o problema do custo de implantação de aterros sanitários é uma das principais restrições a empreendimentos desse tipo, especialmente em municípios pequenos. O Mecanismo de Desenvolvimento Limpo (MDL), ao permitir que os municípios aufiram renda com a venda de créditos de carbono por longo tempo após sua implantação, poderia funcionar como uma forma de estimular a implantação desses aterros e diminuir a restrição de custos de municípios pequenos. A captação do gás produzido no aterro pode ser aproveitada para utilização em projetos de MDL, gerando créditos de carbono. Estes créditos podem ser vendidos no mercado mundial para países que não conseguem cumprir suas cotas de redução de emissões de GEE`s na atmosfera ${ }^{6}$.

\footnotetext{
Um exemplo de implementação de projeto de MDL em aterro sanitário foi na cidade de São Paulo, especificamente no Aterro Bandeirantes, um dos principais da cidade. Em setembro de 2007, os créditos gerados pela captação e utilização do gás do aterro foram negociados na Bolsa de Mercadorias e Futuro (BM\&F), gerando cerca de 800 mil Reduções Certificadas de Emissões (CER's), totalizando R\$34,5 milhões para o município.
} 


\subsection{Município de Viçosa}

O município de Viçosa-MG está localizado na Zona da Mata de Minas Gerais. Segundo IBGE (2010), este município possui aproximadamente 80 mil de habitantes. Sua produção de lixo diária é de mais de 19 toneladas (Secretaria do Meio Ambiente Viçosa, 2010).

O Departamento de Limpeza da cidade, em parceria com a Universidade Federal de Viçosa, realiza em alguns bairros da cidade a coleta seletiva do lixo, que é encaminhado à usina de triagem para ser reciclado.

A cidade possui ainda um aterro controlado, situado a cerca de $10 \mathrm{~km}$ do município, onde o lixo é depositado diariamente. O local possui as plataformas de compostagem e sistema de captação de gás, mas este é descartado para o meio ambiente, contribuindo para o efeito estufa. Assim, pode-se dizer que o município de Viçosa tem grande potencial para implementar projetos de MDL em seu aterro. Desse modo, este contribuiria para a redução de gases de efeitos estufa e geraria recursos financeiros para cobrir os gastos de implementar o aterro sanitário, bem como seus custos operacionais.

\section{METODOLOGIA}

O presente estudo pode ser caracterizado como descritivo, sendo que os resultados almejados foram alcançados através de estudo de caso.

De acordo com Gil (2002), o estudo de caso é uma pesquisa que busca se aprofundar em um ou mais objetos de estudo, de forma que permita adquirir um conhecimento amplo e detalhado. Este é um tipo de pesquisa de natureza empírica e interpretativa, que visa apurar a realidade de um fenômeno e em que situações ele ocorre, principalmente quando os limites entre o fenômeno e o contexto não são totalmente claros (YIN, 1994). Entretanto, o estudo de caso é limitado a somente uma realidade, pois uma vez que este se foca em um único objeto, seus resultados não podem ser generalizáveis. Segundo Ventura (2007), o estudo de caso não aceita um estrutura rígida, mas é possível definir quatro importantes fases: delimitar a unidade de caso; coletar os dados; selecionar, analisar e interpretar os dados; elaborar relatório.

Para responder à questão de pesquisa e atender ao objetivo geral e os objetivos específicos a pesquisa deverá compor-se de três etapas. Na primeira 
etapa será feita entrevista com o engenheiro responsável pela construção e manutenção do aterro sanitário na cidade de Visconde do Rio Branco 7 . Esse aterro foi utilizado como base para levantamento dos custos de implementação, pois essa cidade possui características semelhantes ao município de Viçosa segundo a disposição diária de resíduos sólidos.

Em seguida, na segunda etapa, realizará os cálculos das emissões de gases de efeito estufa do aterro sanitário. Para isso, utilizou-se a metodologia $\mathrm{AM} 001^{8}$ de cálculo das emissões de gases do aterro sanitário. Essas emissões dependem da quantidade de resíduos que o aterro sanitário recebe e dos valores das variáveis usadas na fórmula. No presente trabalho, serão usados três cenários para as emissões de metano, assim podendo calcular as emissões em diferentes perspectivas para os 25 anos de vida útil do aterro sanitário de Viçosa. Estes cenários levam em consideração que a produção de metano depende da composição do lixo e foram baseados no estudo de Vieira et al (2006).

- Cenário baixo: constante de decaimento $\mathrm{k}=0,05$, fração de metano no biogás $\mathrm{F}=55 \%$ e um potencial de geração de metano $\mathrm{L}_{0}=0,15$;

- Cenário mediano: constante de decaimento $\mathrm{k}=0,07$, fração de metano no biogás $\mathrm{F}=55 \%$ e um potencial de geração de metano $\mathrm{L}_{0}=0,175$;

- Cenário alto: constante de decaimento $\mathrm{k}=0,09$, fração de metano no biogás $\mathrm{F}=55 \%$ e um potencial de geração de metano $\mathrm{L}_{0}=0,20$;

Por fim, procederá aos cálculos de viabilidade econômica são utilizadas algumas ferramentas dão suporte para determinar se estes projetos são economicamente viáveis. No presente trabalho utilizar-se-á somente os cálculos do valor presente líquido (VPL) e a taxa interna de retorno (TIR). Para calcular o VPL e a TIR, são necessárias estimativas das receitas e das vendas dos créditos de carbono pela prefeitura de Viçosa. Como é difícil estimar estes preços para o período de 25 anos, preferiu-se construir cená-

Visconde do Rio Branco dista 40 km de Viçosa e possui um aterro sanitário sendo operacionalizado.

8 Fórmula da Metodologia AM 00 I , representa quantidade de metano produzido durante o ano T ()); K é a constante de decaimento; equivale a quantidade de resíduos depositados no ano y (Kg); é igual ao potencial de geração de metano ( ; T representa o último ano de vida útil do aterro; y refere-se ao ano de deposição do resíduo e $F$ corresponde a fração de metano no biogás (\%). 
rios de comportamento de preços. Os cenários utilizados para o cálculo da receita obtida a partir da venda dos créditos de carbono gerados no aterro sanitário de Viçosa serão os seguintes:

- $\quad$ Cenário pessimista: valor do crédito de carbono a $€ 10$. Como se espera um aumento do valor do crédito de carbono no futuro (valor atual: $€$ 12), devido à maior preocupação ambiental, este cenário foi chamado de pessimista.

- $\quad$ Cenário médio: valor do crédito de carbono a $€ 20$. Esse cenário foi denominado como médio porque ele fica entre os outros dois cenários;

- Cenário otimista: valor do crédito de carbono a $€ 30$. Esse cenário foi denominado como otimista porque o valor do crédito de carbono negociado na bolsa de valores hoje gira em torno de $€ 12$.

As taxas de juros utilizadas para fazer os cálculos do VPL de cada cenário irão variar de $6 \%$ até $12 \%$ ao ano, para que se possa verificar a viabilidade econômica do projeto a diferentes custos de oportunidade.

\section{RESULTADOS E DISCUSSÕES}

Nessa seção serão apresentados os custos de implementação e operacional do aterro sanitário, bem como as possíveis receitas obtidas através da venda dos créditos de carbono gerado pelo aterro sanitário. Além disso, procederá os cálculos da viabilidade econômica, determinado no estudo pelo VPL e TIR.

\subsection{Encargos do aterro sanitário}

\subsubsection{Custos de implementação}

Os custos de implantação de um aterro sanitário são aqueles que se referem à preparação do terreno, construção de prédios e instalações, vias de acesso e do projeto de MDL que fornecerá as receitas futuras. De forma detalhada, os custos de implantação são os seguintes: 
1) Usina de triagem de materiais recicláveis: é o local onde ocorre a separação dos resíduos em orgânicos (perecíveis) e não-orgânicos (não-perecíveis). Esse custo foi estimado por meio dos custos de instalação desse mesmo prédio em Visconde do Rio Branco-MG e é um dos maiores custos incorridos na instalação do aterro ( $\mathrm{R} \$ 202.169,06)$.

2) Prédio da administração: é o local onde o gerente do aterro sanitário guarda todos os documentos necessários para o funcionamento do aterro sanitário. O custo associado à construção desse prédio é de $\mathrm{R} \$$ 29.231,00. Esse custo também foi estimado pela comparação com Visconde do Rio Branco-MG.

3) Posto de controle do aterro sanitário: é um anexo da administração onde ficam armazenadas as ferramentas para manutenção do aterro sanitário. O custo da construção do posto de controle é de R\$13.690,84.

4) Fossa séptica do aterro sanitário: são unidades de tratamentos de esgotos domésticos, no caso de um aterro sanitário, uma fossa para o uso dos trabalhadores, onde o esgoto seria armazenado. O custo da construção da fossa séptica é de $\mathrm{R} \$ 3.312,92$.

5) Pátio de triagem da usina de triagem: é o local onde o lixo orgânico, depois de ser coletado na usina de triagem, é levado para ser seco. $\mathrm{O}$ resíduo permanece nesse local por 1,5 dias para ser seco e depois levado para as plataformas (local onde se aterra o lixo). O custo de implantação do pátio da usina de triagem é de $\mathrm{R} \$ 125.753,12$.

6) Projeto de MDL: o custo desse projeto foi calculado com base no custo de outro projeto de MDL desenvolvido no aterro sanitário de Santa Tecla - RS (VANZIN e PANDOLFO, 2005). O custo estimado foi de $\mathrm{R} \$ 218.040,00$.

7) Lagoas facultativas e anaeróbias: são os locais onde o chorume (líquido proveniente da decomposição do lixo) recebe tratamento para não contaminar os lençóis freáticos da região. Os custos de construção dessas lagoas estão associados ao uso de um trator utilizado para fazer a escavação das lagoas. As lagoas possuem um total de $375 \mathrm{~m}^{2}$ e cada hora de trator é R\$60,00 e são necessários 30 minutos para escavar $1 \mathrm{~m}^{2}$. O total dos custos é de $\mathrm{R} \$ 11.250,00$. 
8) Custos do projeto técnico: são incorridos no desenvolvimento do projeto. Estes custos foram estimados por entrevista com o professor Antônio Resende do Departamento de Engenharia Civil da Universidade Federal de Viçosa, especialista no desenvolvimento desse tipo de projeto. O custo é de R $\$ 10.000,00$.

9) Despesas com os funcionários: são relacionadas aos empregados na obra de construção do aterro. Esses custos são referentes a 10 funcionários na obra, com um salário de $\mathrm{R} \$ 510,00$, um engenheiro civil responsável pela obra, com salário no valor de $\mathrm{R} \$ 3.000,00$ e um tratorista, com um salário de $\mathrm{R} \$ 1.000,00$, totalizando $\mathrm{R} \$ 109.200,00$ por um ano, que foi o tempo necessário para construção do aterro sanitário de Visconde do Rio Branco.

10) Custos da rede elétrica: são incorridos para levar os padrões de energia elétrica até o aterro sanitário, pois nele a usina de triagem utiliza energia elétrica e sem ela seria impossível realizar a coleta dos resíduos. Esses dados foram estimados por meio de pesquisa nos custos do aterro de Santa Tecla-RS.

11) Cercamento da área: foi utilizado a metragem total do aterro sanitário, que é de $5.000 \mathrm{~m}^{2}$, utilizando arame farpado com quatro fios. O preço do arame farpado de $500 \mathrm{~m}$ é de 180,00, segundo o site da Gerdau (GERDAU, 2010). O custo total é de R\$7.200,00.

12) Acesso permanente do aterro sanitário: é o calçamento da estrada que fica perto do aterro sanitário e da entrada do aterro. O material utilizado é arenito e paralelepípedo de $\mathrm{R} \$ 3,00 \mathrm{~m}^{2}$ e a área a ser coberta é de $10.000 \mathrm{~m}^{2}$, totalizando $\mathrm{R} \$ 30.000,00$.

Dessa forma, o total de custo de implantação do aterro sanitário na cidade de Viçosa-MG, com uma vida útil 25 anos, seria de R\$ 776.346,94.

\subsubsection{Custos Operacionais (Anuais)}

Os custos operacionais são os custos de funcionamento do aterro sanitário. Estes custos referem-se aos custos de cobertura diária, moni- 
toramento ambiental e pagamento de funcionários. De forma detalhada, eles são os seguintes:

1) Custos de proteção de taludes com grama: sempre que as plataformas chegam ao limite da capacidade de compactação de lixo, tem-se que cobrí-la com grama para que a terra não desça, causando um deslizamento. O preço do $\mathrm{m} 2$ de grama é de $\mathrm{R} \$ 5,00$ e são cobertos anualmente $3.000 \mathrm{~m} 2$, totalizando $\mathrm{R} \$ 15.000,00$ anuais.

2) Cobertura diária: é o uso de terra para cobrir os resíduos nas plataformas. Utiliza-se para esse trabalho um trator. $\mathrm{O}$ salário mensal do tratorista é de cerca de $\mathrm{R} \$ 1.000,00$ o preço do diesel em junho de 2010 era de R \$ 2,00 em Viçosa e são necessários 4 horas diárias para fazer o trabalho. Anualmente, o custo da cobertura diária é de $\mathrm{R} \$ 40.080,00$.

3) Custo do monitoramento operacional: necessários um gerente com salário de $\mathrm{R} \$ 1.000,00$ e quatro funcionários com salário de $\mathrm{R} \$ 510,00$, anualmente, para monitorar um aterro do tamanho daquele de Viçosa. Assim, são necessários R \$ 36.480,00.

4) Custos de monitoramento ambiental: são necessários para fazer a análise dos lençóis freáticos da região, para saber se o chorume não está os contaminando. A análise ambiental custa cerca de $\mathrm{R} \$ 1.000,00$ mensais, totalizando $\mathrm{R} \$ 12.000,00$ anuais.

Dessa forma, o total dos custos operacionais é de $\mathrm{R} \$ 104.280,00$. De forma resumida, os custos de implantação e custos operacionais (anuais) do aterro sanitário de Viçosa são apresentados no quadro 1. 
Quadro 1. Custos de implementação e custos de operacionalização do aterro sanitário de Viçosa.

\begin{tabular}{lr}
\hline \multicolumn{1}{c}{ Custos } & Valor (R\$) \\
\hline & $202.169,06$ \\
1) Usina de triagem de materiais recicláveis & 29.231 \\
2) Prédio da administração & $13.690,84$ \\
3) Posto de controle & $3.312,92$ \\
4) Fossa séptica do aterro sanitário & $125.753,12$ \\
5) Pátio de triagem da usina de triagem & $218.040,00$ \\
6) Projeto de MDL & $11.250,00$ \\
7) Construção das lagoas facultativas e anaeróbias & $10.000,00$ \\
8) Projeto técnico & $109.200,00$ \\
9) Despesas com funcionários & $16.500,00$ \\
10) Rede elétrica & $7.200,00$ \\
11) Cercamento da área & $30.000,00$ \\
\hline 12) Acesso permanente & $\mathbf{7 7 6 . 3 4 6 , 9 4}$ \\
\hline Subtotal & $15.000,00$ \\
\hline \multirow{2}{*}{ 1) Proteção de taludes com grama } & $40.800,00$ \\
2) Cobertura diária & $36.480,00$ \\
3) Monitoramento operacional & $12.000,00$ \\
\hline \multirow{2}{*}{ 4) Monitoramento ambiental } & $\mathbf{1 0 4 . 2 8 0 , 0 0}$ \\
\hline
\end{tabular}

Fonte: Prefeitura de Visconde do Rio Branco (2010)

\subsection{Emissões da linha de base}

Para fazer as estimativas das emissões da linha de base, utilizou-se a metodologia AM001 de cálculo das emissões de gases do aterro sanitário. Essas emissões dependem da quantidade de resíduos que o aterro sanitário recebe e dos valores das variáveis usadas na fórmula. No presente trabalho, conforme determinado serão usados três cenários para as emissões de metano, assim podendo calcular as emissões em diferentes perspectivas para os 25 anos de vida útil do aterro sanitário de Viçosa. A tabela 2 apresenta os valores do cenário baixo, mediano e alto de emissões de metano. 
Viabilidade econômica de projeto de mecanismo de desenvolvimento limpo em aterro sanitário na cidade de Viçosa - MG

Tabela 2. Emissões de metano da linha de base para os cenários baixo, mediano e alto.

\begin{tabular}{cccc|cccc}
\hline \multirow{2}{*}{ Ano } & \multicolumn{2}{c}{ Emissões de metano } & Ano & \multicolumn{3}{c}{ Emissões de metano } \\
& (toneladas de $\mathrm{CO}_{2}$ equivalente) & & \multicolumn{3}{c}{ (toneladas de $\mathrm{CO}_{2}$ equivalente) } \\
\hline & Baixo & Mediano & Alto & & Baixo & Mediano & Alto \\
2010 & 280,80 & 327,60 & 374,40 & 2024 & 582,27 & 768,61 & 945,10 \\
2011 & 299,77 & 355,54 & 412,69 & 2025 & 607,04 & 804,68 & $1.006,42$ \\
2012 & 319,11 & 383,98 & 451,62 & 2026 & 632,30 & 841,43 & $1.060,42$ \\
2013 & 338,81 & 412,94 & 491,21 & 2027 & 653,04 & 878,86 & $1.110,90$ \\
2014 & 358,90 & 437,48 & 531,48 & 2028 & 684,29 & 916,99 & $1.162,27$ \\
2015 & 379,37 & 472,14 & 572,44 & 2029 & 711,04 & 955,84 & $1.214,55$ \\
2016 & 400,23 & 502,72 & 614,10 & 2030 & 738,31 & 995,84 & $1.267,77$ \\
2017 & 421,49 & 533,87 & 656,48 & 2031 & 766,17 & $1.035,73$ & $1.312,95$ \\
2018 & 443,17 & 565,59 & 699,60 & 2032 & 794,46 & $1.076,81$ & $1.377,09$ \\
2019 & 465,26 & 597,89 & 743,46 & 2033 & 823,35 & $1.118,66$ & $1.433,23$ \\
2020 & 487,77 & 630,79 & 768,66 & 2034 & 852,81 & $1.161,30$ & $1.490,39$ \\
2021 & 510,72 & 664,30 & 788,08 & 2035 & 882,84 & $1.204,75$ & $1.548,48$ \\
\cline { 5 - 8 } 2022 & 534,11 & 698,43 & 811,12 & Total & $14.530,39$ & $19.075,54$ & $23.770,34$ \\
2023 & 557,96 & 733,20 & 916,18 & & & & \\
\hline
\end{tabular}

Pode-se notar pela tabela 2 que, o cenário baixo totaliza 14.530,39 toneladas de $\mathrm{CO}_{2}$ equivalente nos 25 anos de vida útil do aterro; o cenário mediano, 19.075,54 toneladas de $\mathrm{CO}_{2}$ equivalente e o cenário alto, 23.770,34 toneladas de $\mathrm{CO}_{2}$ equivalente. Esses valores são relativamente baixos, porque a quantidade de resíduos depositados diariamente é pequena (19 toneladas/ dia). Em Salvador, por exemplo, Vieira et al. (2006) encontraram um valor de 3.572.142 toneladas de $\mathrm{CO}_{2}$ equivalente para o aterro de Canabrava, em Salvador-BA, para 30 anos de vida útil. Já no aterro de Santa Tecla-RS, onde são depositados diariamente cerca de 260 toneladas, a geração de metano prevista em 14 anos de vida útil do aterro é de 596.282 toneladas de $\mathrm{CO}_{2}$ equivalente, uma quantidade muito maior que o aterro sanitário da cidade de Viçosa (VANZIN et al, 2005). Esta pequena geração de metano no aterro de Viçosa irá se refletir no pequeno potencial de geração de créditos de carbono. 


\subsection{Receitas Esperadas}

As receitas esperadas são geradas a partir da venda dos créditos de carbono advindas das emissões evitadas de metano do aterro sanitário. A cotação dos créditos de carbono é determinada pelo mercado internacional, especialmente pela oferta e demanda de empresas e bancos, principalmente europeus. As vendas ou compras dos créditos de carbono ocorrem por meio de bolsas europeias e por corretoras e bancos, e isso ocorre por que os países signatários do Protocolo de Kyoto precisam alcançar suas cotas de reduções de emissões de gases do efeito estufa. A cotação dos créditos de carbono é feita geralmente em euros e, no presente trabalho, a cotação do euro usada será a do dia 27 de maio de 2010, que foi $\mathrm{R} \$ 2,25 / €$.

As emissões do aterro sanitário são geradas com a deposição de lixo da cidade de Viçosa. No ano de 2010, não existiria receita porque as negociações das emissões são referentes à redução do ano anterior. Assim, em 2010 deveriam ser negociados os créditos referentes a 2009, ano em que não houve redução. Como no trabalho foram estipulados três cenários com diferentes preços para o crédito de carbono [um cenário de $€ 10$, outro de $€ 20$ e outro de $€ 30$ ] à medida que se aumenta o preço, consequentemente aumenta-se o valor das receitas esperadas.

Os resultados das receitas esperadas com a venda do crédito de carbono para os três de preços nos cenários baixo, mediano e alto de emissões de metano são apresentados no apêndice 1. Para o cenário mediano e cenário de preço de $€ 10$, a receita total para a vida útil do aterro é de $\mathrm{R} \$ 307.023,89$; para o cenário de $€ 20$, a receita total é de $\mathrm{R} \$ 614.157,88$, e para o terceiro cenário de $€ 30$, a receita total é de $\mathrm{R} \$ 921.206,96$. Para o cenário mediano e cenário de preço de $€ 10$, a receita total é de $\mathrm{R} \$ 402.093,56$; para o cenário de $€ 20$, a receita total é de $\mathrm{R} \$ 804.187,11$ e para o terceiro cenário de $€ 30$, a receita total é de $\mathrm{R} \$ 1.206 .280,67$. E para o cenário alto e o cenário de preço de $€ 10$, a receita total para a vida útil do aterro é de $\mathrm{R} \$ 499.807,53$; para o cenário de $€ 20$, a receita total para os anos são $\mathrm{R} \$ 999.976,01$, e para o terceiro cenário de $€ 30$, a receita total é de $\mathrm{R} \$ 1.499 .968,58$.

Contudo, as receitas para cada ano de funcionamento do aterro sanitário para os três cenários são muito pequenas em relação ao custo operacional do 
aterro sanitário (estimado em R \$ 104.280,00). Desse modo, seria necessário um aporte mensal muito alto por parte da prefeitura do município para cobrir as despesas de operacionalização do aterro, bem como de receitas para sanar o custo de implantação do aterro sanitário ( $\mathrm{R} \$ 776.346,94)$.

\subsection{Cálculos do VPL}

Nesta seção, serão apresentados os cálculos do VPL referentes às receitas e custos do aterro sanitário. Se os valores das receitas não viabilizarem o projeto, serão feitos novos cálculos para saber qual o valor mínimo de venda do crédito de carbono para que este projeto seja viável economicamente.

Os VPLs são calculados através da diferença entre os custos e receitas geradas pelo aterro sanitário. No trabalho, foram especificados que as taxas de juros variariam de $6 \%$ até $12 \%$ ao ano, de forma a englobar situações de maior ou menor custo de oportunidade. A Tabela 4 apresenta os valores dos VPLs para os três cenários de preços em cada cenário de emissões de metano.

Pode-se notar que todos os valores são negativos para todas as taxas de juros. Com isso, o VPL mostra que o projeto é inviável economicamente. Isso ocorre por que todos os valores das receitas esperadas com a venda dos créditos de carbono são inferiores ao custo operacional do aterro sanitário.

Como não se encontrou VPL positivos, novos cálculos foram efetuados para saber qual são os valores dos créditos de carbono que viabilizariam o projeto. A Tabela 5 apresenta os valores do VPL que viabilizam o projeto para o cenário baixo. Os cálculos mostram que os valores tornam-se positivos quando o valor do crédito de carbono é maior ou igual a $€ 165$,valores muito além dos praticados atualmente, que giram em torno de $€ 12$. Dessa forma, parece pouco provável que uma situação como esta seja observada no futuro. 
Tabela 4. VPL referentes aos cenários de emissão de metano e cenários de preços do credito de carbono

\begin{tabular}{|c|c|c|c|}
\hline \multirow{3}{*}{ Taxa de juros } & \multicolumn{3}{|c|}{ Preço do crédito de carbono por cenário } \\
\hline & \multicolumn{3}{|c|}{ Cenário Baixo } \\
\hline & $€ 10$ & $€ 20$ & $€ \mathbf{3 0}$ \\
\hline $6 \%$ & $-1.990 .883,31$ & $-1.855 .248,21$ & $-1.719 .608,10$ \\
\hline $7 \%$ & $-1.884 .320,91$ & $-1.764 .330,45$ & $-1.644 .339,99$ \\
\hline $8 \%$ & $-1.792 .137,14$ & $-1.685 .407,19$ & $-1.578 .677,24$ \\
\hline $9 \%$ & $-1.711 .977,52$ & $-1.616 .540,44$ & $-1.521 .103,35$ \\
\hline $10 \%$ & $-1.641 .917,53$ & $-1.556 .145,62$ & $-1.470 .373,70$ \\
\hline $11 \%$ & $-1.580 .380,68$ & $-1.502 .070,04$ & $-1.425 .462,39$ \\
\hline $12 \%$ & $-1.526 .070,040$ & $-1.455 .795,06$ & $-1.385 .520,09$ \\
\hline \multirow{2}{*}{ Taxa de juros } & \multicolumn{3}{|c|}{ Cenário Mediano } \\
\hline & $€ 10$ & $€ 20$ & $€ \mathbf{3 0}$ \\
\hline $6 \%$ & $-1.950 .790,87$ & $-1.775 .053,32$ & $-2.132 .317,11$ \\
\hline $7 \%$ & $-1.849 .260,81$ & $-1.694 .210,26$ & $-2.009 .539,14$ \\
\hline $8 \%$ & $-1.761 .314,53$ & $-1.623 .761,96$ & $-1.903 .611,44$ \\
\hline $9 \%$ & $-1.684 .736,64$ & $-1.562 .058,67$ & $-1.811 .740,15$ \\
\hline $10 \%$ & $-1.617 .718,54$ & $-1.507 .747,63$ & $-1.731 .650,33$ \\
\hline $11 \%$ & $-1.558 .777,27$ & $-1.459 .714,72$ & $-1.661 .481,65$ \\
\hline $12 \%$ & $-1.506 .691,70$ & $-1.414 .038,38$ & $-1.599 .706,36$ \\
\hline \multirow{2}{*}{ Taxa de juros } & \multicolumn{3}{|c|}{ Cenário Alto } \\
\hline & $€ 10$ & $€ 20$ & $€ \mathbf{3 0}$ \\
\hline $6 \%$ & $-1.909 .475,02$ & $-1.692 .421,62$ & $-1.475 .368,21$ \\
\hline $7 \%$ & $-1.813 .132,82$ & $-1.621 .954,28$ & $-1.430 .775,74$ \\
\hline $8 \%$ & $-1.729 .546,03$ & -1.560 .224 .97 & $-1.390 .903,91$ \\
\hline $9 \%$ & $-1.656 .649,52$ & $-1.505 .884,43$ & $-1.335 .119,34$ \\
\hline $10 \%$ & $-1.592 .755,29$ & $-1.457 .821,14$ & $-1.322 .886,99$ \\
\hline $11 \%$ & $-1.536 .477,63$ & $-1.415 .115,44$ & $-1.293 .753,25$ \\
\hline $12 \%$ & $-1.486 .674,06$ & $-1.377 .003,11$ & $-1.267 .332,15$ \\
\hline
\end{tabular}

Fonte: Resultados da pesquisa. 


\subsection{Possíveis valores do crédito de carbono que viabilizam o projeto.}

Nessa subseção realizou-se o cálculo dos valores dos créditos de carbono que podem viabilizar o projeto de MDL no município de Viçosa. As tabelas 5, 6 e 7 apresentam os resultados para os três cenário determinados.

Tabela 5. Valores que viabilizam o projeto para o cenário baixo.

\begin{tabular}{cccc}
\hline \multirow{2}{*}{ Taxa de juros } & \multicolumn{3}{c}{ Preço do crédito de carbono } \\
\cline { 2 - 4 } & $€ 160$ & $€ 165$ & $€ 170$ \\
\hline $6 \%$ & $-\mathrm{R} \$ 60.856,40$ & $\mathrm{R} \$ 3.876,75$ & $\mathrm{R} \$ 68.609,89$ \\
$7 \%$ & $-\mathrm{R} \$ 178.141,33$ & $-\mathrm{R} \$ 120.910,15$ & $-\mathrm{R} \$ 63.678,96$ \\
$8 \%$ & $-\mathrm{R} \$ 275.546,46$ & $-\mathrm{R} \$ 224.669,43$ & $-\mathrm{R} \$ 173.792,40$ \\
$9 \%$ & $-\mathrm{R} \$ 356.765,97$ & $-\mathrm{R} \$ 311.298,03$ & $-\mathrm{R} \$ 265.830,09$ \\
$10 \%$ & $-\mathrm{R} \$ 424.756,86$ & $-\mathrm{R} \$ 383.916,43$ & $-\mathrm{R} \$ 343.076,01$ \\
$11 \%$ & $-\mathrm{R} \$ 481.894,58$ & $-\mathrm{R} \$ 445.032,49$ & $-\mathrm{R} \$ 408.170,39$ \\
$12 \%$ & $-\mathrm{R} \$ 530.094,33$ & $-\mathrm{R} \$ 496.668,95$ & $-\mathrm{R} \$ 463.243,57$ \\
\hline
\end{tabular}

Fonte: Resultados da pesquisa.

A Tabela 6 é referente ao cálculo do VPL das emissões calculadas para o cenário mediano. $\mathrm{O}$ valor do crédito de carbono do cenário mediano que tornam positivos os cálculos do VPL é de $€ 130$ ou superior, muito além dos valores praticados atualmente.

Tabela 6. Tabela referente aos valores que viabilizariam o projeto para o cenário mediano.

\begin{tabular}{cccc}
\hline \multirow{2}{*}{ Taxa de juros } & \multicolumn{3}{c}{ Preço do crédito de carbono } \\
\cline { 2 - 4 } & $€ 120$ & $€ 125$ & $€ 130$ \\
\hline $6 \%$ & $-\mathrm{R} \$ 31.565,66$ & $-\mathrm{R} \$ 48.201,02$ & $\mathrm{R} \$ 35.163,62$ \\
$7 \%$ & $-\mathrm{R} \$ 45.743,99$ & $-\mathrm{R} \$ 72.252,53$ & $-\mathrm{R} \$ 98.761,06$ \\
$8 \%$ & $-\mathrm{R} \$ 340.136,43$ & $-\mathrm{R} \$ 274.991,64$ & $-\mathrm{R} \$ 209.846,84$ \\
$9 \%$ & $-\mathrm{R} \$ 418.457,96$ & $-\mathrm{R} \$ 360.404,54$ & $-\mathrm{R} \$ 302.351,11$ \\
$10 \%$ & $-\mathrm{R} \$ 483.677,86$ & $-\mathrm{R} \$ 431.679,00$ & $-\mathrm{R} \$ 379.680,15$ \\
$11 \%$ & $-\mathrm{R} \$ 538.177,75$ & $-\mathrm{R} \$ 491.373,42$ & $-\mathrm{R} \$ 444.569,09$ \\
$12 \%$ & $-\mathrm{R} \$ 583.874,60$ & $-\mathrm{R} \$ 541.548,27$ & $-\mathrm{R} \$ 499.221,95$ \\
\hline
\end{tabular}

Fonte: Resultados da pesquisa. 
A tabela 7 é referente ao cálculo do VPL das emissões calculadas para o cenário alto. Os cálculos mostram os valores do crédito de carbono que viabilizariam o projeto. Quando o crédito de carbono está sendo comercializado a $€ 100$ ou mais, o projeto torna-se viável. Porém, como já se salientou, esse valor é muito elevado em relação ao comercializado hoje, o que torna sua observação pouco provável.

Tabela 7.Valores que viabilizam o projeto, para o cenário alto.

\begin{tabular}{cccc}
\hline \multirow{2}{*}{ Taxa de juros } & \multicolumn{3}{c}{ Preço do crédito de carbono } \\
\cline { 2 - 4 } & $€ 100$ & $€ 105$ & $€ 110$ \\
\hline $6 \%$ & $\mathrm{R} \$ 44.005,60$ & $\mathrm{R} \$ 152.532,30$ & $\mathrm{R} \$ 261.059,00$ \\
$7 \%$ & $-\mathrm{R} \$ 92.525,94$ & $\mathrm{R} \$ 3.063,33$ & $\mathrm{R} \$ 98.652,60$ \\
$8 \%$ & $-\mathrm{R} \$ 205.656,48$ & $-\mathrm{R} \$ 120.995,95$ & $-\mathrm{R} \$ 36.335,42$ \\
$9 \%$ & $-\mathrm{R} \$ 299.763,70$ & $-\mathrm{R} \$ 224.381,15$ & $-\mathrm{R} \$ 148.998,61$ \\
$10 \%$ & $-\mathrm{R} \$ 378.347,92$ & $-\mathrm{R} \$ 310.880,85$ & $-\mathrm{R} \$ 243.413,77$ \\
$11 \%$ & $-\mathrm{R} \$ 444.217,91$ & $-\mathrm{R} \$ 383.536,81$ & $-\mathrm{R} \$ 322.855,72$ \\
$12 \%$ & $-\mathrm{R} \$ 499.635,48$ & $-\mathrm{R} \$ 444.800,01$ & $-\mathrm{R} \$ 389.964,53$ \\
\hline
\end{tabular}

Fonte: Resultados da pesquisa.

Em resumo, foram feitos novos cálculos para se descobrir quais valores viabilizariam o projeto. No cenário baixo, o valor do crédito deve ser de $€$ 165 ou mais; no cenário mediano, o valor do crédito deve ser de $€ 130$ ou mais e no alto, de $€ 100$ ou mais. Esses valores viabilizariam o projeto, mas como o valor do crédito de carbono comercializado atualmente é de $€ 12$, ou seja, os valores encontrados nos cenários baixo, mediano e alto são muito maiores do que o da atual conjuntura, não se espera que essas condições sejam observadas no futuro.

\subsection{Cálculos da TIR}

Nesta seção, serão apresentados os cálculos da taxa interna de retorno (TIR). A Tabela 8 apresenta os valores da TIR para o cenário baixo.

Os valores do crédito de carbono que fazem com que a TIR seja positivo, para o projeto de MDL no aterro sanitário da cidade de Viçosa começam com 115 euros por cada tonelada de $\mathrm{CO}_{2}$. A esse valor, a taxa interna de retorno é igual a $0,21 \%$. 
Tabela 8. Valores da TIR para o cenário baixo.

\begin{tabular}{cc}
\hline Valor do crédito de carbono $€$ & TIR \\
\hline 115 & $0,21 \%$ \\
120 & $0,94 \%$ \\
125 & $1,62 \%$ \\
130 & $2,26 \%$ \\
135 & $2,87 \%$ \\
140 & $3,45 \%$ \\
145 & $4,00 \%$ \\
150 & $4,54 \%$ \\
155 & $5,05 \%$ \\
160 & $5,55 \%$ \\
165 & $6,03 \%$ \\
170 & $6,50 \%$ \\
\hline
\end{tabular}

Fonte: Resultados da pesquisa.

Aumentando o valor dos créditos de carbono, o valor da TIR também aumenta: a $€ 120$, a TIR é igual a $0,94 \%$; a $€ 125$, a TIR é igual a $1,62 \%$, até chegar ao último valor calculado de $€ 170$ a tonelada, em que a TIR é igual a 6,50\%. Todavia considera-se improvável que os valores da tonelada de $\mathrm{CO}_{2}$ atinja esses preços, haja vista os preços praticados hoje.

Tabela 9. Valores da TIR para o cenário mediano.

\begin{tabular}{cc}
\hline Valor do crédito de carbono $€$ & TIR \\
\hline 90 & $0,61 \%$ \\
95 & $1,47 \%$ \\
100 & $2,28 \%$ \\
105 & $3,03 \%$ \\
110 & $3,74 \%$ \\
115 & $4,41 \%$ \\
120 & $5,05 \%$ \\
125 & $5,66 \%$ \\
130 & $6,24 \%$ \\
\hline
\end{tabular}

Fonte: Resultados da pesquisa. . 
A Tabela 9 apresenta os valores da TIR referentes ao cenário mediano. Os valores do crédito de carbono que fazem com que a TIR seja positiva são $€ 90$ ou mais por cada tonelada de $\mathrm{CO}_{2}$. A esse valor a taxa interna de retorno é igual a $0,61 \%$. Aumentando o valor dos créditos de carbono, o valor da TIR também aumenta: a $€ 130$ a tonelada, a TIR é igual a 6,24.

Tabela 10. Valores do TIR para o cenário alto.

\begin{tabular}{cc}
\hline Valor do crédito de carbono $€$ & TIR \\
\hline 70 & $0,94 \%$ \\
75 & $2,01 \%$ \\
80 & $2,99 \%$ \\
85 & $3,90 \%$ \\
90 & $4,75 \%$ \\
95 & $5,55 \%$ \\
100 & $6,30 \%$ \\
105 & $7,02 \%$ \\
110 & $7,71 \%$ \\
115 & $8,38 \%$ \\
\hline
\end{tabular}

Fonte: Resultados da pesquisa.

A Tabela 10 apresenta os valores da TIR referente ao cenário alto. Para este cenário, os valores que viabilizam o projeto são $€ 70$ ou mais. A esse valor, a taxa interna de retorno é igual a $0,94 \%$. A $€ 75$, a TIR é igual a $2,01 \%$; a $€ 80$ igual a $2,99 \%$ e o último valor calculo, $€ 115$ a tonelada, corresponde uma a TIR é igual a $8,38 \%$.

\section{CONCLUSÕES}

Os mecanismos de flexibilização foram criados no protocolo de Kyoto como meio para os países signatários reduzirem suas emissões de gases do efeito estufa. O mecanismo de desenvolvimento limpo é um dos tipos de mecanismos de flexibilização. Estes podem ser implementados em vários tipos de projetos. Desses, os projetos de MDL em aterros sanitários possuem grande potencial para desenvolvimento no país, uma vez que estes visam reduzir as emissões por meio da queima de metano de resíduos sólidos. 
Os resultados alcançados no projeto mostraram que a geração de créditos de carbono para o município de Viçosa seria muito pequena, fazendo com que a receita seja pequena em relação aos custos de se implementar um aterro sanitário com projeto de MDL. As ferramentas utilizadas para se estabelecer a viabilidade econômica do projeto, como o VPL e a TIR, para os nove cenários, foram decisivas para determinar que o projeto é inviável, pois o VPL para os cenários das emissões de metano (baixo, mediano e alto) e para todos os cenários de preço (10, 20 e 30 euros) foram negativos. A TIR, nas mesmas condições acima, não pode ser determinada, porque todos os valores do saldo do fluxo de caixa são negativos, a esses preços.

Com os novos cálculos do VPL e da TIR, conseguiu-se estabelecer quais valores do crédito de carbono tornariam este projeto viável. Considerando que atualmente o valor de cada crédito de carbono está em torno de $€ 12$, os valores calculados estão muito longe de se tornarem reais.

Assim, esse tipo de empreendimento para municípios de pequeno porte, como é o caso da cidade de Viçosa, é muito oneroso, pois na situação atual da cidade, as receitas que a venda dos créditos de carbono gerariam seriam muito menores do que os custos de se implementar e de funcionamento do aterro.

Uma alternativa possível seria que os municípios vizinhos da cidade de Viçosa fizessem um consórcio para a construção do aterro sanitário e depositassem lá todos os seus resíduos, aumentando assim a geração de metano e gerando mais créditos de carbono e, consequentemente, mais receitas. Desse modo, o projeto poderia ser viável nas condições atuais de mercado, ou seja, com o acúmulo de resíduos das outras cidades, a geração de renda seria maior e a venda dos créditos de carbono não dependeria de um possível aumento de seu preço, tornando o projeto viável.

\section{ECONOMIC FEASIBILITY OF CLEAN DEVELOPMENT MECHANISM PROJECT IN LANDFILL IN VIÇOSA - MG}

\section{Abstract}

The Clean Development Mechanism (CDM) was developed in the Kyoto Protocol in order that the signatory countries to reduce their emissions of greenhouse gases effects. In the case of Brazil, there is the development 
of CDM projects applied to landfills. The costs of the landfill are a major constraint on this kind enterprise, especially in small municipalities. The Clean Development Mechanism (CDM) allows municipalities to earn income by selling carbon credits for a long time after its implementation, which might function as a way to stimulate the deployment of these landfills and to reduce the cost constraint of small municipalities. In this sense, the present paper aims to calculate the economic feasibility of implementing a CDM project at the landfill in Viçosa-MG. To investigate the economic feasibility of this project, Net Present Value (NPV) and Internal Rate of Return (IRR) are calculated. The calculations showed that NPV and IRR for this project would be feasible if price of carbon credits had been much larger than it is today. The conclusion is that the project is economically unfeasible. The main reason is that the amount of waste produced daily by the city is relatively small (19 tons / day). As suggestion, one possible way for this project to work economically without causing financial damage to the city would be the formation of a consortium among several cities to increase the amount of waste lay in daily, and the division of implementation and operation costs of the landfill.

Keywords: Economic Analysis of Projects, Project Management, Economic Feasibility.

\section{JEL Classification: Q5}

\section{REFERÊNCIAS}

BORTHOLIN, E.;GUEDES, B.D. Efeito Estufa. Disponível em: $<$ http:// www.educar.sc.usp.br/licenciatura/2003/ee/Efeito_Estufa.html $>$. Acesso em 09 jan. 2010.

BRASIL-PRESIDENCIA DA REPÚBLICA. Lei No 10.257, de 10 de julho de 2001. http://www.planalto.gov.br/ccivil_03/leis/leis_2001/110257.htm. Acesso em 25 de julho de 2010. 
CARVALHO, M.M.C. Análise ambiental do aterro sanitário do município de Anápolis Estado de Goiás. 129 f. 2011. Dissertação (Sociedade, Tecnologia e Meio Ambiente)-Pós em Sociedade, Tecnologia e Meio Ambiente, Centro Universitário de Anápolis- UNIEVANGÉLICA, Anápolis, GO, 2011.

CAVALCANTE, S. FRANCO, M. F. A. Profissão perigo: percepção de risco à saúde entre os catadores do Lixão do Jangurussu. Revista Mal Estar e Subjetividade. v.7 n.1 Fortaleza mar. 2007.

CONAMA- Licenciamento Ambiental de sistemas de disposição final dos resíduos sólidos urbanos gerados em municípios de pequeno porte. Disponível em: < http://www.mma.gov.br/port/conama/res/res02/res30802. html >. Acesso em: 8 mar. 2010.

CONAMA. Resolução CONAMA n 001 do dia 23 de janeiro de 1986. Disponível em: $<$ http://www.antt.gov.br/legislacao/Regulacao/suerg/ Res001-86.pdf>. Acesso em: 04 fev. 2010.

COTTA, M. K. Quantificação de biomassa e análise econômica do consórcio seringueira-cacau para geração de créditos de carbono. 2005. 89f. Dissertação (Mestrado em Ciência Florestal)-Universidade Federal de Viçosa, Viçosa, MG, 2005.

FRANGETTO, F.W.; GAZANI, F.R. Viabilização jurídica do Mecanismo de Desenvolvimento Limpo (MDL) no Brasil - O Protocolo de Kyoto e a cooperação internacional. São Paulo: Peirópolis; Brasília, DF: IIEB Instituto Internacional de Educação no Brasil, 2002. 477p.

FUNASA-Fundação Nacional da Saúde. Doenças Infecciosas e Doenças Infecciosas e Doenças Infecciosas e Parasitárias. 2 edi. Brasília, 2000. Disponível em: http://bvsms.saude.gov.br/bvs/publicacoes/funasa/GBDIP001_total.pdf. Acesso em: 25 junho 2010.

GIL, A. C. Como elaborar projetos de pesquisa. $4^{\circ}$ ed. São Paulo, Atlas. 2008. 
IBGE - Instituto Brasileiro de Geografia e Estatística. Pesquisa Nacional de Saneamento Básico 2000. Brasília, 2000. Disponível em: $<$ http://www. ibge.gov.br/home/presidencia/noticias/27032002pnsb.shtm>. Acesso em 16 jan 2010.

IBGE - Instituto Brasileiro de Geografia e Estatística. Pesquisa Nacional de Saneamento Básico 2000a. Brasília, 2000. Disponível em:

$<$ http://www.ibge.gov.br/home/estatistica/populacao/condicaodevida/pnsb/ lixo_coletado/lixo_coletado110.shtm>. Acesso em 15 jan. 2010.

IBGE - Instituto Brasileiro de Geografia e Estatística. Pesquisa Nacional de Saneamento Básico 2000b. Brasília, 2000.

Disponível em: <http://www.ibge.gov.br/home/presidencia/noticias/27032002pnsb.shtm>. Acesso em 15 jan. 2010.

LEME, R. M.; CUNHA. K.B. Adicionalidade em projetos de MDL e a cogeração no setor sucroalcooleiro. 2004. 10f. Dissertação (Mestrado em Planejamento de Sistemas Energéticos) - Faculdade de Engenharia Mecânica da Unicamp. Campinas, SP, 2004.

LUPATINI, G. Desenvolvimento de um sistema de apoio à decisão em escolha de áreas para aterros sanitários. 2002. Dissertação (Mestrado em Engenharia Ambiental)-Universidade Federal de Santa Catarina, Florianópolis, SC, 2002.

Ministério da Ciência e Tecnologia. Procedimentos para Submissão de Projetos de MD à Comissão Interministerial de Mudança Global do Clima. Brasília 2005. Disponível em: <http://www.mct.gov.br/upd blob/0015/15798.pdf> Acesso em 10 jun. de 2010. Acesso em: 5 julho 2010.

PENTEADO, C. L.C.; MELO, T. R.B. Como Projetos de MDL Contribuem para o "Desenvolvimento Sustentável"? IV Encontro Nacional da 
Anppas.4,5 e 6 de junho de 2008, Brasília - DF. Disponível em: <www. anppas.org.br/.../cd/.../GT11-928-691-20080510183015.pdf>. Acesso 24 jun 2010.

REICHERT, G. A. Aterro sanitário: projeto, implantação e operação. Porto Alegre, RS. ABES, 2000.

VELOSO, F.; COSTA, J. T. Equação do lixo. 08 jan. 2004. Disponível em: $<$ http://www.oeco.com.br/todos-os-colunistas/51-flavia-velloso-e-joao-teixeira-da-costa/16671-oeco_10489>. Acesso em11 fev 2010.

VENTURA, M. M.O estudo de caso como modalidade de pesquisa. Revista da Sociedade de Cardiologia do Estado do Rio de janeiro (SOCERJ), v. 20, n.5, p.383-386, set/out, Rio de Janeiro, 2007.

VIEIRA, R.P.; CASSEMIRO, E.; NETO J.L.C. Reversão do Passivo Ambiental: uma Implantação de MDL em um Aterro Sanitário de Salvador. In: SEGeT - Simpósio de Excelência em Gestão e Tecnologia da Associação Educacional Dom Bosco, 3, 2006, Rio de Janeiro. Anais eletrônicos. Rio de Janeiro. 2006. Disponível em: <www.aedb.br/anais-seget/gs_pos.htm>. Acesso 05 ago 2010.

VIDIGAL, F. A. M. O protocolo de Kyoto, o mecanismo de desenvolvimento limpo e as formas de circulação dos créditos de carbono. Disponível em: <http://apache. camara.gov.br/portal/arquivos/camara/ internet/publicacoes/estnottec/tema14/2007_2054.pdf\%3E >. Acesso em: 19 mar. 2011.

YIN, R.K.Case study research. Design and methods. $2^{\mathrm{a}}$ ed., USA: Sage Publications, 1994. 


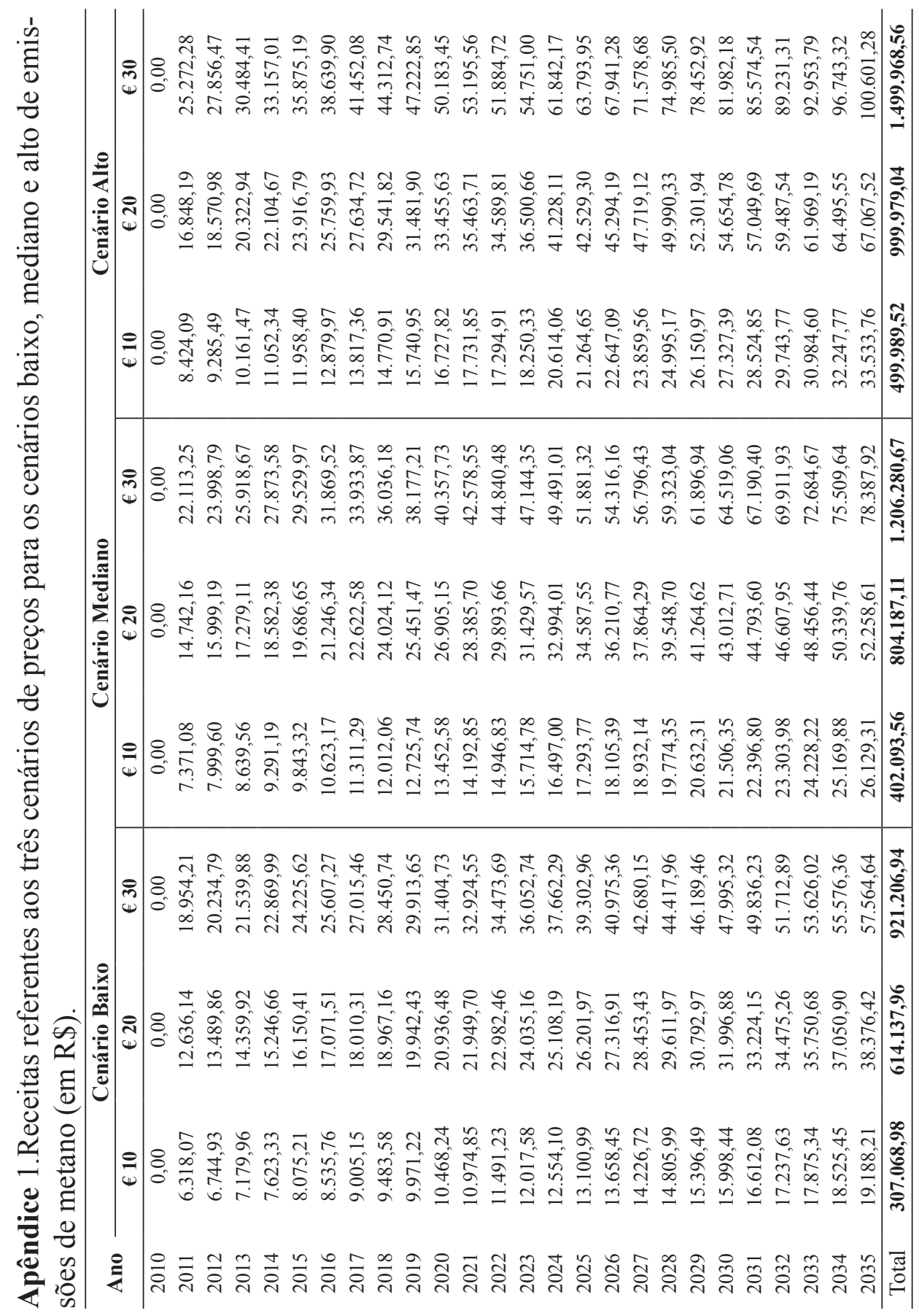

